\title{
Overcoming the English-Language Barrier
}

\author{
Terry J. Mahoney \\ Scientific Editorial Service, Research Division, Instituto de Astrofísica \\ de Canarias, E-38205 La Laguna, Tenerife, Spain. e-mail: tjm@ll.iac.es
}

\begin{abstract}
Astronomers from non-English-speaking countries, who form a sizeable proportion of the astronomical research community, are obliged to communicate the results of their investigations in a language that is not their own. Consequently, good science is frequently masked by poor command of English, which can create an unnecessary barrier to the communication of scientific results. A suggested method of surmounting the language barrier is the setting up of scientific editorial services in at least the major astronomical centres. It is further argued that journal editors, rather than scientific referees, should be responsible for judging the linguistic and stylistic quality of articles presented for publication. The peer-review system would then be restricted exclusively to the scientific rather than linguistic content of papers presented.

The scientific Editorial Service of the Instituto de Astrofísica de Canarias, in operation since 1996 , is briefly described in this context.
\end{abstract}

\section{Introduction}

English has attained an overwhelming hegemony since the Second World War and is now firmly established as the lingua franca of science. Scientists who fail to publish in English run the risk of lack of international recognition of their work with occasionally catastrophic consequences (e.g., Osawa and the prediction of the existence of the $\mathrm{C}_{60}$ molecule). The membership list of the IAU reveals that $\sim 60 \%$ of working astronomers are non-anglophone (Mahoney 2001), yet all peer-reviewed articles must conform to high standards of written English. Some even claim that there is an "Anglo-Saxon bias" towards work produced by non-anglophone workers (Carter-Sigglow 1997) - especially towards work by those from developing countries (Umakantha 1997).

\section{Surmounting the Language Barrier}

\subsection{The scientific community}

The scientific community can help lessen the language burden of non-anglophone researchers by restricting peer review solely to questions of science and subsuming all questions relating to language usage into the editorial process. At the very least, referees who take it upon themselves to comment on the standard of English of a presentation should be prepared to make detailed suggestions 
on how the language may be improved instead of issuing such useless blanket statements as, 'the English of this paper could do with some improvement.' The question to be addressed is exactly how it may be improved, and journal staff are usually better equipped to handle this sort of problem. When a paper is rejected or referred back to the authors for revision, the authors have every right to expect to be told precisely what modifications are required of them in terms of both content and language.

\subsection{Publishers}

Publishers can (and most do) contribute by providing clear instructions to authors and explaining what happens to an article in the publishing process (a subject on which author knowledge tends to be vague or non-existent).

\subsection{Institutions}

Research centres need to develop a keen awareness of the language problem and offer courses in communication techniques. Where economically feasible, they could set up in-house editorial services to vet articles for grammar, spelling, adherence to journal styles, etc. Where this is too expensive, such services might be set up by pooling limited resources on a regional, national, or even international basis.

\subsection{Author self-help}

Above all, non-anglophone authors can help themselves by learning to regard English as an essential working tool, rather than as an objectionable hurdle to be cleared with the minimum effort. They should ensure that their writing possesses a clear logical structure, write with a target journal in mind, read the journal instructions carefully, run a spell-checker (with caution!) through their work, learn all they can about editing and publishing and acquire a minimum set of up-to-date standard reference works (dictionaries, etc.) - see poster by Mahoney (this volume, pp. 357-362).

\section{What Sort of Things Can Go Wrong?}

It is first of all important to separate language difficulties from inability to think coherently. Language problems tend to occur among scientists at all levels, from doctoral students to heads of research departments, anglophones and non-anglophones, whereas as lack of coherent structure in writing is often associated with lack of writing experience. New researchers often lack an elementary knowledge of how a paper should be structured and how an argument should be developed. Often, their work will have a distinctly classroom air about it, with many references to undergraduate textbooks and no proper insight into current research. Most doctoral students, however, soon pass the juvenilia stage and mature remarkably rapidly; a small number, however, never quite grasp the basics of research writing, and their papers always need drastic overhauling before they are submitted for peer review. For this reason, research centres need to instill the precepts of good research writing in terms of how to structure an article and how to relate their writing effectively to other published work. 
Apart from training, it is a good idea for new researchers always to submit their work to some form of internal review-not, I hasten to add, for the purposes of vetting the science, but rather to ensure that the paper is properly structured and well argued, which should be well within the capabilities of any competent researcher.

Common errors not related to language are: incomplete or incorrect references, non-adherence to journal style, poor presentation of illustrations and tables (e.g. unlabelled or illegibly labelled axes, etc.), inclusion of non-English words, phrases, sentences and occasionally entire paragraphs, failure to finish the article, and non-use of spelling checkers to weed out typos and the grosser misspellings. All of these oversights are due to carelessness (and many of them are not restricted to non-anglophone authors!). Authors must learn the need for good presentation at the start of their careers, and research centres can do much in this respect by providing relevant courses in authorship and publishing practices in astronomy. An excellent work that all academic authors should obtain a copy of is Beth Luey's Handbook for Academic Authors (Luey 1997), which provides many useful insights into all aspects of academic publishing.

Language difficulties are of an entirely different order and need to be dealt with differently. It is probably unrealistic to expect small non-anglophone research centres to be able to afford the provision of English classes at a suitable level for their research staff, but larger institutions may be able to do something in this respect. Incidentally, given the international nature of astronomical research these days, this also applies to anglophone centres, which often employ staff of many nationalities. Ultimately, however, it is up to individual researchers to strive constantly to improve their mastery of English, which, after all, is as essential a working tool to them as a knowledge of, say, statistics or calculus. While the aim must always be to write to publishable standard, this skill will take considerable time to acquire and is conditional upon such factors as previous language training and innate ability; however, all researchers must know sufficient English to avoid outright blunders and at least avoid saying the opposite to what they intend to say (only too easy to do in English, with its inscrutable verbal phrases and innumerable other booby traps for the unwary).

But it is not all just about writing. Non-anglophones are also at a severe disadvantage when it comes to making an oral presentation at a conference. Effective communication in public is a vital skill for all researchers, who need to make a good impression when under fire on the podium. Trainee researchers should take every opportunity of practising this skill in house before venturing to face the music at an international conference (see Gosling 1999 for some useful pointers), and those centres that can afford to provide courses in making public presentations should try to do so.

\section{Which English?}

From a linguistic point of view, there are many varieties of English, but as far as science is concerned only two need be considered seriously. American journals and publishers invariably require American English; in Britain, Ireland, continental Europe and the Commonwealth countries, British English is the norm. This is not as alarming as it might sound at first sight, since in reality 
we are mainly talking about questions of spelling and punctuation (it is unwise to try to be idiomatically "bilingual" in both). As far as academic English is concerned, the difference between the two is fairly minimal, full coverage of all the difficulties that are likely to arise being given in the references in the poster by Mahoney (this volume, pp. 357-362).

\section{Essential Working Tools}

The basic reference tools for research writing are given in the poster presentation by Mahoney (this volume, just cited). On a purely language level, however, the non-anglophone could usefully browse the Web site of Oxford University Press (http://www.oup.co.uk), which is one of the world's leading English language teaching publishers (its ELT publications, for all proficiency levels, are listed at http://www1.oup.co.uk/elt/). An essential prerequisite for all non-anglophone writers of English is the best affordable bilingual dictionary, of which the latest edition should always be sought. A difficulty here is that such works do not always exist, even for some of the major languages, although the revolution that has taken place in commercial lexicography over recent decades has gradually transformed the situation from what it was, say, thirty years ago. As an example, present-day bilingual Spanish-English/English-Spanish dictionaries are more comprehensive, orders of magnitude more useful and of much higher quality than those published not so long ago.

\section{Scientific Editorial Services}

All non-anglophone (and many anglophone) research centres could benefit from setting up-however provisionally - some form of editorial unit dedicated to the task of checking articles and proceedings contributions for English, internal consistency, correct referencing, adherence to journal style, etc. Such scientific editorial services (SESs) should be based on the following concepts:

- Editors should be astronomers, not departmental secretaries (who usually have better things to do with their limited time)

- The decision on whether or not to use the service must be the authors' alone

- All corrections must be indicated either on paper, using standard markup symbols (their use to be explained to authors), or in the electronic text file

- All corrections must be agreed upon between the editor and the authors, the latter always having the final say

- Articles must be corrected, not rewritten, and the original wording must be respected (provided it conforms to general standards of idiomatic correctness)

- Articles should be written and corrected with a particular journal in mind 
- Authors should undertake to use any feedback from the editorial service to improve their standards of written English and general presentation: the proper role of an SES is to correct articles not to write them for the authors

- With regard to the editing of conference proceedings, editorial services should be used in a strictly advisory capacity: it is the job of the named proceedings editors to edit their own proceedings

\section{English at the IAC}

The Scientific Editorial Service of the Instituto de Astrofísica de Canarias (IAC) has been in operation since 1996. The SES is manned full time by an astronomer at the IAC's Research Division. The bulk of the work received for correction is in the form of research articles and contributions to conference proceedings, with occasional translation from Spanish into English for the IAC's Web page. Paper copies of double-spaced manuscripts are marked up using standard symbols and the corrections keyed in to the electronic file. The paper copy and electronic file are then returned to the author, who is responsible to submitting the corrected MS to the journal. The typical turnaround time is about two days for a letter and from four days upwards for a main journal article. Letters take priority, followed by main journal articles and proceedings contributions (in that order). Occasionally there are bottlenecks when several MSS arrive over a short period; in such cases it might take weeks to return the corrected article to the author. About half the total published output of the IAC - from main journal articles to proceedings contributions-is pre-edited by the Service before being submitted for publication; to date, over 200 articles and many proceedings contributions have been processed by the SES. IAC authors who use the Service find that many of the usual language problems with referees tend to arise much less frequently or not at all.

\section{Conclusions}

The English language is seen by many non-anglophone scientists as an obstacle in publishing their work. However, there are many ways in which the language barrier can be minimized by the scientific community (in redefining the role of referees in the peer-review system), by publishers (in explaining to authors what happens to their MSS after submission), by research institutions (by cultivating an awareness of the language problem and providing the necessary training in combating it) and finally by authors themselves (in learning to regard language as an essential working took that needs to be constantly honed to perfection). Scientific editorial services could usefully be set up on institutional, regional or even national levels (according to available funding) to correct articles for English (and perhaps journal style). One such service has been in operation at the IAC since 1996 and is viewed positively by those authors who use it, with the result that many of the common complaints about the language hurdle have either been largely overcome or eradicated altogether. 
Acknowledgments. I thank the IAU for its invitation to attend the General Assembly. My visit was funded by the Instituto de Astrofísica de Canarias.

\section{References}

Carter-Sigglow, J. 1997, Nature, 385, 764.

Gosling, P. J. 1999, Scientist's Guide to Poster Presentations (New York: Kluwer)

Luey, B. 1997, Handbook for Academic Authors, 3rd edn. (Cambridge: Cambridge University Press)

Mahoney, T. J. 2001, in Organizations and Strategies in Astronomy, ed. A. Heck (Dordrecht: Kluwer), p. 185.

Umakantha, N. 1997, Nature, 385, 764.

\section{Discussion}

Iwanizewska regretted that Mahoney's paper had not been presented at the beginning of the Session. Other speakers might then have not presented their own papers in such an incomprehensible way - with, for example, no abstracts presented on the screen. Speakers from English-speaking countries were particularly guilty. She thanked speakers not from English-speaking countries who had so painstakingly prepared material to be projected - so we could see what they were talking about. Please would native English-speakers do the same in future!

Kochhar observed that spell-checkers can be a nuisance: none of them would accept his name! He was worried that in-house checking of papers could lead to scientific censorship. He also recalled that Hidayat had said at the Kyoto General Assembly in 1997 that "Bad English is the international language of science"! Mahoney agreed that spell-checkers should be used with caution but they could weed out the most glaring spelling mistakes and typographical slips. He certainly agreed that there should not be censorship but young researchers sometimes submit immature papers to journals and more experienced workers should check that their papers are up to standard. He agreed with Hidayat, but felt that bad English should be eliminated whenever possible - simply to reduce the delays between submission and publication.

Kosionidis said that the dominance of English made difficulties for visits by astronomers to a non-English-speaking country. In most developing countries it is difficult for local students to benefit fully from visits by astronomers from the U.S., the U.K. or Europe. Mahoney suggested that such countries should take full advantage of any schemes that allow non-anglophone astronomers to visit English-speaking research centres, where they could gradually develop fluency in English.

Pasachoff recalled an incident in "Le Petit Prince" by Antoine de SaintEuxpéry. St-Exupéry describes an "astronome Turque" who wore native costume while addressing an international meeting of astronomers (perhaps the IAU?). The Turkish astronomer describes the discovery of the asteroid on which the Little Prince lives, but no-one listens to him because of the way he dresses. 
Only when he returns later wearing Western dress is his discovery accepted! Pasachoff thought that a reasonable proficiency in English may play the role of non-Western story in this mocking parable. He noted that everyone in the room, although from many different countries, was wearing western dress! 